\title{
Improvement of the properties of aluminium alloys
}

\author{
Korostelev V. F., Bolshakov A. E. \\ Dept. of Process Automation, Vladimir State University, Vladimir, Russia \\ Email address: \\ giess300@mail.ru (Korostelev V. F.), a.e.bolshakov@mail.ru (Bolshakov A. E.)
}

\section{To cite this article:}

Korostelev V. F., Bolshakov A. E.. Improvement of the Properties of Aluminium Alloys. Advances in Materials. Vol. 3, No. 5, 2014, pp. 58-62. doi: 10.11648/j.am.20140305.15

\begin{abstract}
The article describes the improvement of the properties of aluminium alloys under pressure application of up to $400 \mathrm{MPa}$ to a liquid or crystallizing metal. A cybernetic model has been developed. Three phases of the alloy compressibility under pressure were investigated. The results of microstructure studies are indicated, the focus has been made on the nonuniform composition within the limits of dendritic cells. Pressure influence on the formation of crystallization centers and their growth was demonstrated. The relationship between hardness and the content of separate alloy components and of the applied pressure was illustrated.
\end{abstract}

Keywords: Crystallization, Aluminium Alloys, Improvement of Properties, Pressure Application, Changes of the State of Alloys, Atomic Interactions

\section{Introduction}

The classification dividing aluminium alloys according to their process characteristics into cast and wrought, into heattreatable and non-heat-treatable significantly depends on the fact that an alloy composition is made by choosing the components with no respect to the external influence on the formation of alloy properties.

In this article pressure applied to a liquid or crystallizing metal is chosen as an external influence factor.

Pressure influence on the process of the formation of alloy properties has not been theoretically studied; there is a certain lack of patent and sci-tech information on this problem.

The studies and projects [1-4] carried out at Vladimir State University have led to the development of the cybernetic model of the improvement of alloy properties.

It is suggested that the formation of the alloy characteristics with a certain composition should be implemented under conditions of pressure application onto a molten metal before the process of crystallization according to the law which defines deliberate impact on pair-wise, triple and other atomic interactions and correlations.

The indicated conception is schematically illustrated in Fig.1

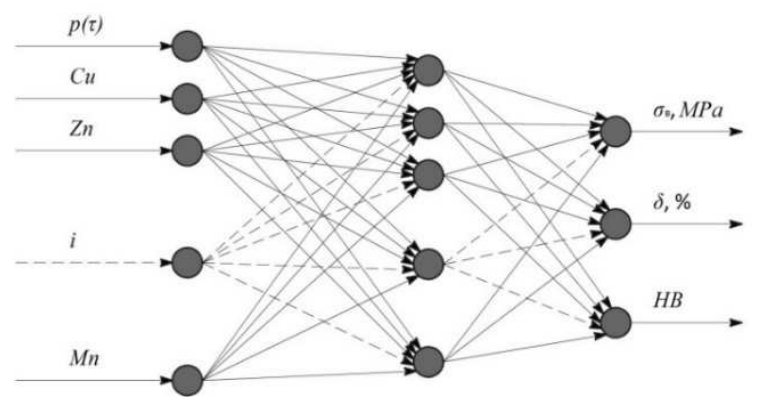

Fig. 1. Cybernetic model of the improvement of alloy properties

Legend: $\mathrm{p}(\tau)$ - pressure as a function of temperature; $\sigma-$ ultimate resistance; $\delta$ - specific elongation; HB- hardness.

\section{Process of Formation Properties}

In contrast to the traditional engineering process, the molten metal of a certain composition with the overheating of $\Delta \mathrm{t}=150 \ldots 200 \mathrm{~K}$ is fed to a passage of a rigid container, where injection plungers moving with a certain speed implement the pressure application law $\mathrm{p}(\tau)[3,4]$.

In this case the whole volume of the melt contracts according to the law $\varepsilon(\tau)$, where $\varepsilon(\tau)$ - is a relative compressibility, i.e. volume contraction to the whole amount of the melt ratio expressed in a percentage.

The analysis of the received oscillograph records has 
shown that the pressure application of $400 \mathrm{MPa}$ to the B95alloy causes $\varepsilon$-value of $10 \%$.

The changing of $\varepsilon$-value has three definite stages: a- the compression by $4-5 \%$ when the relatively low pressure of $100-150 \mathrm{MPa}$ is applied; $\mathrm{b}-$ the compression by $5-6 \%$ when the pressure is increased up to $400 \mathrm{MPa}$; $\mathrm{c}$ - the compression by 2-3 under the pressure of $400 \mathrm{MPa}$ (See Fig.2).

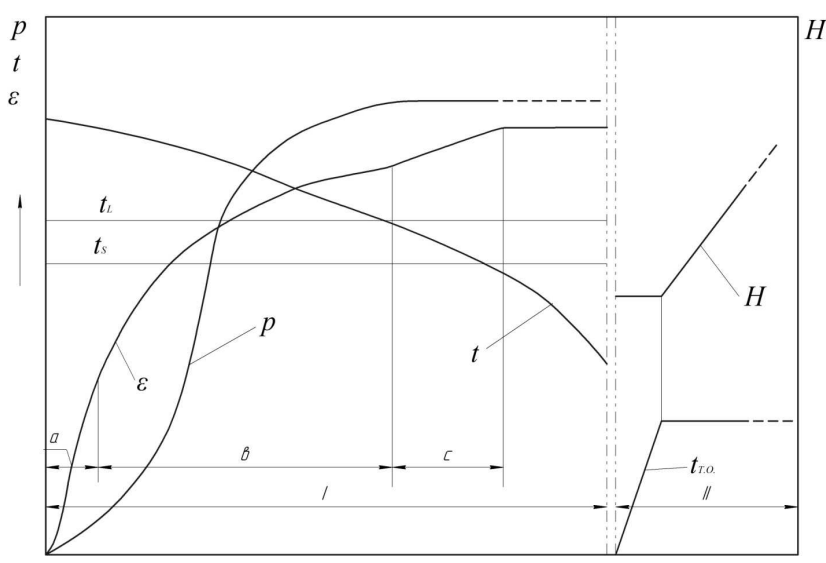

Fig. 2. Two stages of the engineering process

It can be assumed that the a-phase determines uniform inmetal distribution of gases, eliminates their diffusion and the formation of large inclusions.

In the b-phase the melt reaches the state of a compressed spring, when the pressure around the pressing plungers spreads through the whole amount of the melt. At the beginning of this stage the metal behavior is alike the behavior of a liquid under hydrostatic pressure. At the end of the stage relative atomic displacement due to the spring repulsive forces is constrained. As a result the pressure on the shrinkage compensation should be increased.

In the c-phase the passage from liquid to the solid state is connected with the step-like volume reduction. Described here is a purely mechanical aspect of atomic interactions which reveals the features of the formation of a solid defectless metal without voids, microporosity or segregation [2].

\section{Analysis of Microstructures}

The examination of the phases from the point of view of the pressure effect on the changes in physicochemical and mechanical properties of alloys should be paid greater attention.

The characteristic microstructure of an alloy, shown in Fig.3, has some essential differences:

- the section of the $80 \mathrm{~mm}$ alloy sample has a uniform surface and central structure;

- the structure represents light crystallites of the a-solid solution (hereinafter referred to as dendritic cells, or DC) and peripherally set proeutectoid constituents (PC);

- there are no boundaries between DC and PC zones.

It follows, therefore, that in the b-phase crystallization centers with a relatively high melting temperature appear, which - according to the microstructural analysis - are formed of atoms of pure aluminium forcing out other elements which form the compounds with lower crystallization temperature.

It is timely to note that under all-round compression the process of structure-forming is not simultaneous in the whole volume, as the authors of the work [5] comment.

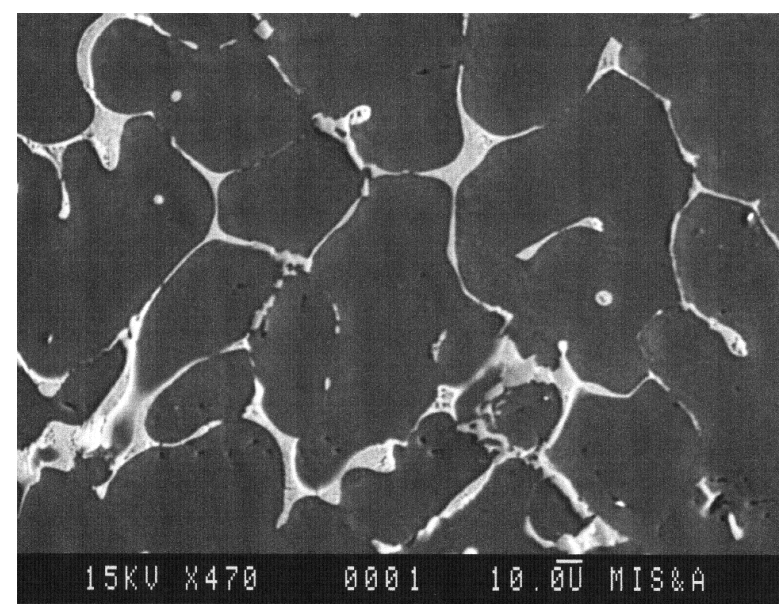

Fig. 3. Microstructure of alloy B95. $200 \mathrm{MPa}$

In the whole volume the centers appear followed by directional crystallization; the thermodynamic drive force of the latter is not the temperature field gradient but the concentration gradient.

Industrial processes of fabrication of metal products based on pressure application, e.g. liquid metal forging, are directed toward the production of a required pressurization value. Pressure time-changes are not controlled.

It is easy to imagine that the parameters of the microstructure, shown in Fig.3, comply with some definite law $\operatorname{pl}(\tau)$.

The nature of the microstructure shows that large dendritic cells are situated inside the outline of proeutectoid constituents. Such structure is typical for equilibrium crystallization, though the maximum p1-pressure was only $200 \mathrm{MPa}$. The p2-pressure rise up to $400 \mathrm{MPa}$ causes the formation of the structure in which proeutectoid constituents are singled out as separate inclusions, and the dendritic cells form a field with no well-defined interface (Fig.4).

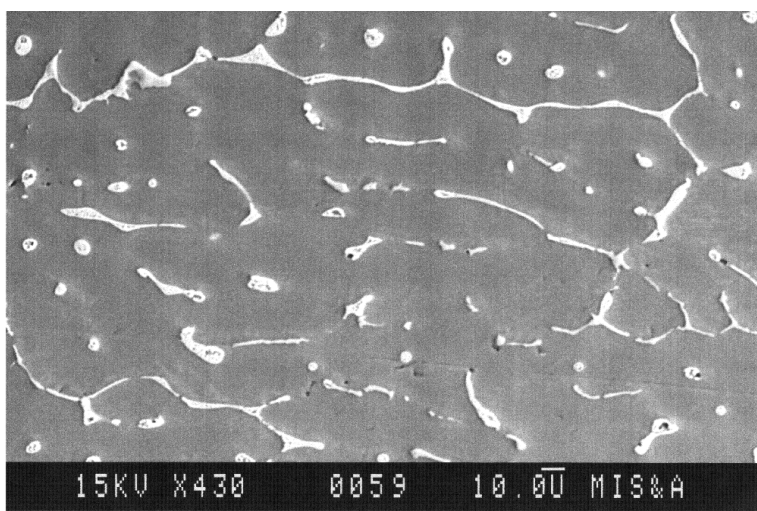

Fig. 4. B95-alloy microstructure. Applied pressure is $400 \mathrm{MPa}$ 
The rise of p3-pressure up to $500 \mathrm{MPa}$ leads to the reduction on the number of proeutectoid constituents, and growing dendritic cells make boundaries - including largeangle - where the particles of proeutectoid constituents can be situated. The reduction of proeutectoid constituents may be connected with the fact that alloy components are dissolved in dendritic cells (Fig.5).

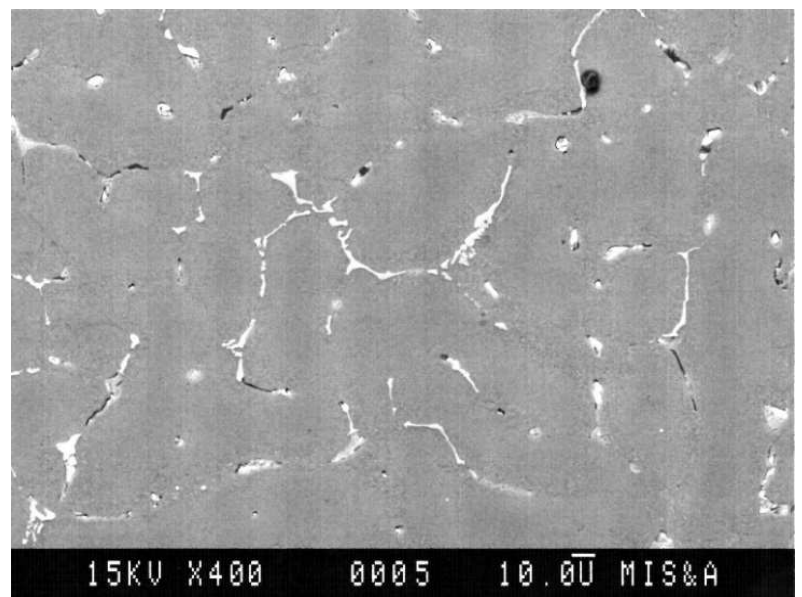

Fig. 5. B95-alloy microstructure. Applied pressure is $500 \mathrm{MPa}$

When the alloy, cooling to the environmental temperature, is heated up to tt.o. $=120{ }^{\circ} \mathrm{C}$ and left for 10 hours holding, then the hardness $\mathrm{HB}=80$ will rise to $\mathrm{HB}=120$ (Fig.2, Step II)

As seen from Fig.4, it may be connected with the dispersion particles (DP) release of proeutectoid constituents inside dendritic cells. The segregation of dendritic cells in this case confirms the assumption about the directed character of the formation of structural components.

It follows that the higher is the speed of pressure application, the more centers will appear and the less are the time-periods in which isolation diffusion will develop and various phases will be built. The higher is the applied pressure level, the higher is the possibility to fixate the atomic relative position typical for the liquid state. Since the atomic position in the liquid state significantly differs from atomic position after the process of crystallization, the described effect can be applied in practice in order to attain an amorphous structure.

During the process of pressure application to a liquid metal the fixation of alloy components into associated groups (AG) may take place due to the increasing density of covalent interactions. This will lead in turn to the inhibition of the formation of equilibrium phases.

Fast pressure application increases the AG-probability. In this case the conditions are created under which the entropy of a compressed liquid-alloy will be decreasing much faster than crystal entropy. When reaching a certain compression ratio the liquid metal may acquire the amorphous state.

Thus changing the pressure application law we can reach a wide spectrum of structures including crystalline, quasicrystalline, quasi-amorphous, amorphous.

Going back to Fig.1, it is important to note that during the process of studying the connectionist model, we can define weight ratio values of the interference of pressure and other alloy components on different characteristics.

It should be emphasized that pressure application - like fast cooling - switches an alloy into the state which is far from equilibrium.

An alloy as a multi-component system, switched by the fast pressure application into a strongly non-equilibrium state, possesses unique properties which define the possibility of the future phase transformations according to different scenarios.

It follows that the use of pressure application for the fabrication of metal products from new alloys with a combination of definite properties can be fulfilled in two stages: I - alloy transformation into a strongly nonequilibrium state; II - temperature-time handling (Fig.2).

The presented scientific-methodological approach has been carried out during engineering of the aluminium-based alloy used for the production of internal-combustion engine pistons.

\section{Discussion of Research Results}

In order to study pressure influence on the process of the formation of mechanical properties of aluminium alloys, the developed cybernetic model (Fig.1) has been formalized and represented in the form of a neural-network one[6].

The wrought alloys B95 and D16 have been chosen as the basis to the learning sample of the neural network model. The planned experiment has been carried out [7]; its variable values were altering during the experiment and are shown in Table 1.

Table 1. Running values in the planned experiment

\begin{tabular}{lllll}
\hline & $\mathbf{C u}, \boldsymbol{\%}$ & $\mathbf{M g}, \boldsymbol{\%}$ & $\mathbf{Z n}, \boldsymbol{\%}$ & Pressure, MPa \\
\hline Min.value & 1,4 & 1 & 0 & 0 \\
Max.value & 5 & 4 & 4,5 & 500 \\
\hline
\end{tabular}

The received data were processed by the STATISTICA 10 software. The diagrams in Fig.6,7,8 show the effect of pressure and of percentage of alloy elements on the hardness of the received product without any additional thermal treatment.

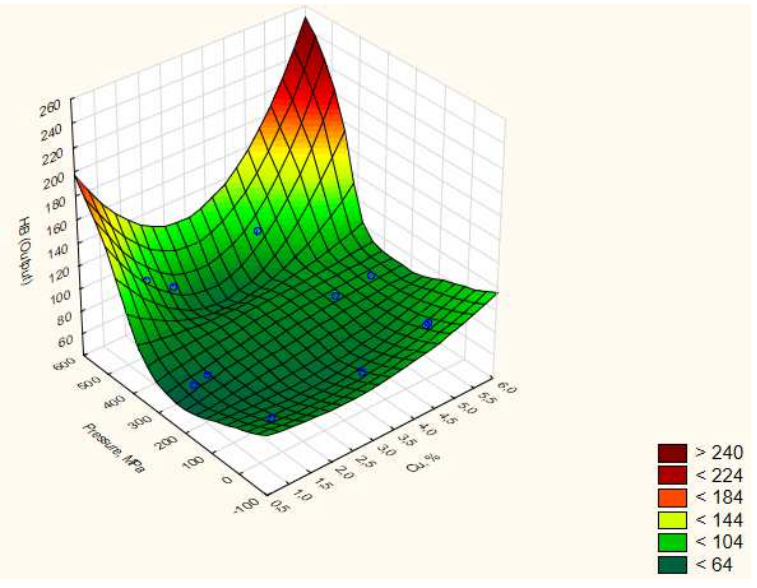

Fig. 6. Hardness-pressure/copper concentration relation. 
Fig. 6 shows that the influence of copper contents on the hardness of aluminium alloys is irrelevant, if the pressure higher than $400 \mathrm{MPa}$ has not been applied to a crystallizing metal.

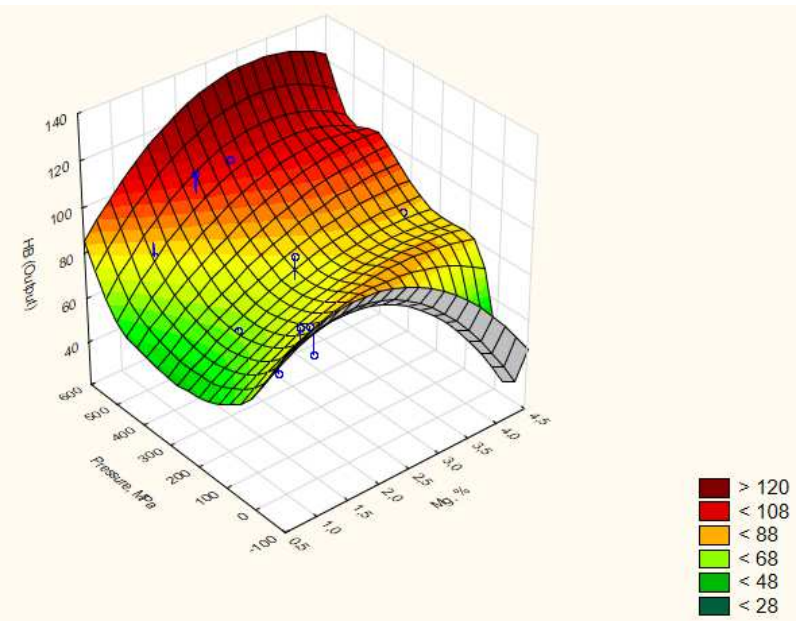

Fig. 7. Hardness-pressure/magnesium concentration relation.

The hardness of the obtained alloys demonstrates a significant increase, as the concentration of magnesium grows.

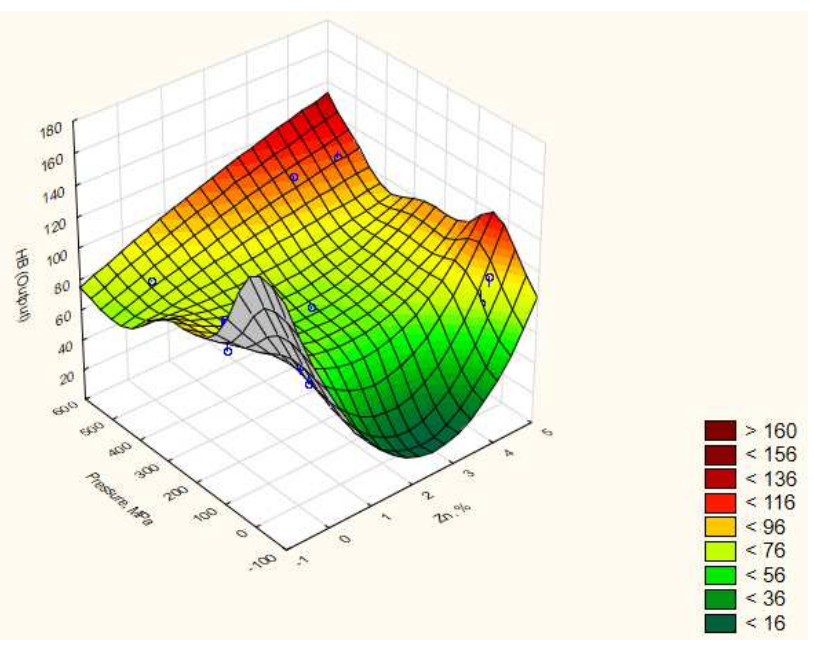

Fig. 8. Hardness-pressure/zinc concentration relation.

The influence of zinc concentration on the hardness is ambiguous; the rise happens only by maximum pressure values.

The diagrams (Fig.6-8) show that the pressure influence varies and depends on the composition of an alloy. In this respect some specific features can be defined:

- It is evident that the increase in hardness becomes apparent at the applied pressure of $300 \mathrm{MPa}$ and higher;

- The established relationships have a complex character, so the use of linear approximations may lead to the evaluation mistakes in the combined influence of several factors;

- The pressure effect on the hardness reveals to a greater extent at the zinc concentration level up to $4 \%$; further increase in the zinc concentration does not provide any observable effect.

Mutual influence of alloying elements does not give an opportunity to estimate the exposure level of pressure on the hardness of wrought aluminium alloys in general, so it is necessary to perform calculations for each alloy separately.

After the study of the neural network model and the program creation an opportunity appeared to predict the hardness of an alloy for each case.

\section{Conclusion}

It is necessary to note that the use of neural network models for the prediction of alloy characteristics has certain advantages compared to the traditionally used industrial empiric methods. The opportunity of quantitative influence evaluation on the test properties of one factor or another attracts the most attention. At that the number of factors can be relatively large. The interference of several factors can also be estimated.

In the submitted paper a limited number of factors have been studied. It is therefore impossible to consider the influence of alloy components on a particular property level with respect to the atomic-electronic interactions. Thus it is appropriate to continue the investigation in the direction of compilation of information on a number of properties - but not only on one property, e.g. hardness - which depend on magnetism, electric or thermal phenomena, etc.

\section{References}

[1] Korostelev V.F. Theory, technology and automation of casting processes with pressure application. Moscow: New technologies, 2004. 224 p. (rus)

[2] Kachak V.V., Korostelev V.F., Khromova L.P. Nanotechnologies and alloys hardening. Moscow: New technologies, 2011. 240 p. (rus)

[3] Korostelev V.F., Bolshakov A.E. Process control of steel production. European Applied Sciences is an international. No.2. 2013(January) P.195-197. ISSN 2195-2183. (OKT Publishing. Schwieberdingersten 5970435. Stuttgart, Germany).

[4] Korostelev V.F. The development of the neural-network model of the alloy crystallization process under pressure. Journal paper / Korostelev V.F., Bolshakov A.E. // Mechatronics, automation, management. No.10, 2011. P.50-55. (rus)

[5] Herlach D.M., Galenko P.K., Holland-Moritz D. Metastable solids from undercooled melts. Amsterdam: Elsevier, 2007. P.423.

[6] F. Musharavati, A.S.M. Hamouda, Application of artificial neural networks for modelling correlations in age hardenable aluminium alloys, Journal of Achievements in Materials and Manufacturing Engineering 41/1-2 (2010) 140-146. 
[7] Hattel J. Fundamentals of Numerical Modelling of Casting Processes. Denmark: Polytechnisk Forlag, Kgs. Lynsby, 2005.

P. 540. 